\title{
Borracha, gás e tiro: impressões sobre Cidades rebeldes
}

\author{
Christian Gilioti ${ }^{1}$
}

HARVEY, David; MARICATO, Ermínia; ŽIŽEK, Slavoj; DAVIS, Mike et al. Cidades rebeldes: Passe Livre e as manifestações que tomaram as ruas do Brasil. São Paulo: Boitempo/Carta Maior, 2013, 112 p.

A penosa construção de nós mesmos se desenvolve na dialética rarefeita entre o não ser e o ser outro.

Paulo Emílio Salles Gomes

O terremoto calca em cinzas a cidade, Tremem cem outras, cambaleando estão, E a barulheira berra sob o chão. Percy Shelley ${ }^{2}$

Em junho de 2013, o país parecia pegar fogo. Ônibus queimavam nas metrópoles, pedágios no interior; no campo, e mais ainda na cidade, o lixo acumulado nas esquinas era posto em chamas improvisando barricadas (incapazes de conter, mas, ao menos, prejudicavam o avanço das forças policiais). Servindo de escudo, também entulhos e tapumes eram erguidos por moças e rapazes que apostavam na força dos paus, pedras e

I Graduado e mestrando em Filosofia pela Faculdade de Filosofia, Letras e Ciências Humanas da Universidade de São Paulo (USP, São Paulo, SP, Brasil). Pesquisa as formas artísticas de parte do cinema nacional da última década e suas imbricações com a cultura e a política contemporâneas. E-mail: christiangilioti@yahoo.com.br

2 Em gesto de camaradagem intelectual - livre, comum e fraterna - o poema foi apresentado a mim pelo amigo Daniel Lago Monteiro que, muito embora sempre em busca de erudição, não perde de vista o mundano. 
gritos diante da saraivada de balas e bombas de efeito "moral" disparadas pelas tropas de choque. A truculência, que fazia suas vítimas (na favela, fatais) e produzia comoção nacional, era seletivamente explorada e ideologicamente retorcida - pela grande mídia, por meio de imagens espetaculares, sobretudo na TV. Entretanto, na contramão das expectativas recorrentes, a indignação dava indícios de crescimento acelerado... Até que, depois de duas semanas, devido à adesão massiva de diferentes parcelas da população, principalmente dos jovens, a revolta contra o aumento das tarifas do transporte "público" conquistou voltagem histórica, não obstante, forçando o recuo dos mais diversos representantes do poder estatal, terminando vitoriosa em mais de cem cidades.

Em síntese, era mais ou menos esse o clima quando a editora Boitempo, em parceria com a Carta Maior, lançou o livro Cidades rebeldes: Passe Livre e as manifestações que tomaram as ruas do Brasil (publicado em julho de 2013). Trata-se de uma coletânea de textos acerca da onda insurgente que, de modo inesperado e até mesmo inimaginável, veio à tona ${ }^{3}$. $\mathrm{O}$ conjunto figura como uma composição de ensaios elaborados no calor momento - ou, se preferirmos, em meio ao gás lacrimogênio - que, em certa medida, contribui para o debate político contemporâneo independentemente da sequência de protestos que culminou com a redução do valor das tarifas de ônibus. Com isso, não se pretende afirmar, evidentemente, que a insurreição de junho apresenta valor secundário ou marginal em relação às questões desenvolvidas em cada um deles. Na verdade, o próprio fenômeno, em função de seu caráter imprevisto e também da intensidade e da dimensão atingidos, por certo obrigou os autores, de um lado, a explorarem as possíveis causas da eclosão e, de outro, a delimitarem recortes para suas abordagens. No limite, de um inspirador exercício de análise de conjuntura, composto

3 Inaugurando a coleção Tinta Vermelha, além da apresentação "As vozes das ruas: as revoltas de junho e suas interpretações" de Raquel Rolnik e dos comentários na quarta capa de Paulo Arantes e Roberto Schwarz, encontram-se no livro os textos: “Não começou em Salvador, não vai terminar em São Paulo”, do Movimento Passe Livre de São Paulo; “É a questão urbana, estúpido!”, de Ermínia Maricato; “A liberdade da cidade", de David Harvey; "Quando a cidade vai às ruas”, de Carlos Vainer; "A rebelião, a cidade e a consciência", de Mauro Luis Iasi; "Estrada de metal pesado", de Mike Davis; "Será que formulamos mal a pergunta?", de Silvia Viana; "O transporte público gratuito, uma utopia real”, de João Alexandre Peschanski; "Territórios transversais", de Felipe Brito e Pedro Rocha de Oliveira; "As Jornadas de Junho", de Lincoln Secco; "Sob a sombra do precariado", de Ruy Braga; "A vez do direito social e da descriminalização dos movimentos sociais", de Jorge Luiz Souto Maior; "Mídia, rebeldia urbana e crise de representação", de Venício A. de Lima; "Em São Paulo, o Facebook e o Twitter foram às ruas", de Leonardo Sakamoto e "Problemas no Paraíso", de Slavoj Žižek. 
por dezoito perspectivas que, por vezes apresentando diferentes graus de antagonismo entre si, resgatam as tensões motivadas pelo ímpeto de superação da intervenção política conformada, exclusivamente, à atividade intelectual.

No entanto, há problemas ou, se preferirmos, algumas lacunas no que se refere ao alcance das reflexões que integram o livro. Três perguntas clássicas, bastante comuns entre os estudiosos de teoria da ação coletiva, por exemplo, ainda permanecem em parte sem resposta, a saber: Quem exatamente foi às ruas durante os protestos? Por que foram às ruas, isto é, quais os motivos que os levaram às manifestações? Que tipo de experiência cultural criou o repertório tanto de indignação como também de ação dos participantes dos protestos? Além disso, é notável como a coletânea, em geral, prioriza intelectuais e análises circunscritos ao eixo Rio-São Paulo, evidenciando certa limitação na compreensão dos acontecimentos de junho em sua escala nacional e em sua multiplicidade regional, por vezes marcada por questões locais.

Evidentemente que, de maneira variada, boa parte dos textos buscou dar conta de tais lacunas. Seria exagero afirmar que os autores de Cidades rebeldes primam pelo empenho de objetividade? Objetividade que não significa, precisamente, reflexão neutra e, tampouco, garantia de lucidez. Negar ao fenômeno o que lhe é próprio pode ser menos uma questão de honestidade ou de talento intelectual e mais dificuldade concreta. Como sugeria Brecht, a imparcialidade política é ilusória, enquanto a consciência crítica é trabalho pesado. Mesmo aquele que escolhe não tomar partido inexoravelmente já conformou para si - e, por certo, também à sua visão de mundo - uma posição parcial. Em contrapartida, se há épocas em que a adesão partidária do pensamento, ao confrontar o plano das ideias com o terreno prático, torna possível renovar o fôlego da reflexão teórica e da ação política, o inverso também é verdade. A vinculação intelectual aos ideais de um grupo politicamente organizado e hegemônico, ou ao menos representativo de setores da sociedade, por vezes produz obscurantismo. Situações - às vezes irremediáveis - em que a chamada intelligentsia articulada aos Partidos da Ordem acaba por padecer de certo arrefecimento analítico, balizado pelo consentimento de incontáveis concessões e capitulações que se justificariam em nome da manutenção do poder, nem sempre está orientada conscientemente por motivos escusos, antes, sim, pela expectativa de implantação de um programa partidário supostamente emancipatório e consistente - ainda que em ritmo paulatino ou, se preferirmos, de modo lento, gradual e seguro. 
No caso de Cidades rebeldes, podemos dizer que o atual "imbróglio" da esquerda brasileira se manifesta - ainda que de modo discreto. Deixando os intelectuais estrangeiros provisoriamente de lado, mas utilizando-os como parâmetro, ao leitor é possível (não sem algum esforço) identificar no livro dois grandes campos que divisam o embate ideológico do esquerdismo nacional. Muito embora genericamente críticos ao capitalismo enquanto sistema, cada lado reserva para si mesmo posturas distintas diante da conjuntura política, sobretudo porque ambos a compreendem igualmente de forma distinta. Ao longo da resenha tentaremos sugerir, apresentando alguns dos pontos de vista dos autores, parte das contradições e dilemas (não apenas ideológicos, mas também práticos) que colocam em choque os dois campos. Em síntese, pode-se dizer que no centro da querela se encontra a própria definição do que nossas esquerdas atualmente entendem por "velho" e "novo" - em termos políticos e econômicos, de maneira geral, mas especialmente no que se refere às formas coletivas de organização e luta, assim como às técnicas de contenção e controle da população. Todavia, outra dimensão das posições em conflito recai inevitavelmente sobre o significado do lulismo que, consolidado por mais de uma década, permite ser observado em perspectiva. O problema reside menos na desilusão gerada pela frustração das expectativas em torno da chegada de um partido de massas ao poder e sim na profunda afinidade entre ele e a reatualização mais do que eficiente dos dispositivos de gestão do capitalismo no país, a qual combina desenvolvimentismo e autoritarismo, não mais à moda antiga. Assim, o leitor desconfiado da ordem estabelecida e amigo do contraditório poderá apreciar no livro uma sequência de hipóteses que às vezes ultrapassam os limites dos discursos defasados pelo jogo de cena que encerra as disputas partidárias, especialmente em torno das eleições, favorecendo assim à montagem de um novo quebra-cabeça com o qual a história parece nos desafiar. Textos que ampliam os sentidos atualmente convencionais da política e da crítica, superando análises de tipo "institucionalista" que, mesmo quando se mostram independentes das tramas rígidas e comprometedoras da realpolitik, normalmente inflacionam a esfera político-institucional em detrimento das imbricações econômicas e sociais que também atuam, interferem, reconfiguram e até pervertem o próprio funcionamento do estado, enquanto instituição gestora - sobretudo de riquezas, mas também de pessoas.

Isto posto, partamos agora para algumas das análises, em termos específicos. Quando a procura dos nexos que estruturam o processo histórico é abandonada, ou posta em segundo plano, os efeitos não são triviais. Um deles, bastante nocivo ao pensamento crítico, é a idealização 
da democracia. Transformado em abstração, o regime aparentemente garantidor das "liberdades individuais" ao mesmo tempo passa a ser invocado como valor em si. Neste sentido, quanto há de naturalização da violência do poder público e banalização do sofrimento social na perspectiva de quem delira legitimação do "Estado Democrático de Direito" no Brasil? Em resposta a isso, após a apresentação de Raquel Rolnik (notável pela capacidade de articulação da miríade de temas em debate) o texto que inaugura a coletânea é assinado pelo Movimento Passe Livre de São Paulo (MPL-SP). Em função do reconhecimento do Estado brasileiro como uma instituição autoritária que privilegia a classe proprietária, o grupo de inspiração autonomista é favorável à reinvenção e experimentação de novas formas e instâncias de decisão política e entende que os protestos deflagraram um ativismo espontâneo e popular precisamente disruptivo: a rua, via de regra mais um entre outros tantos espaços nos quais impera a heteronomia, consolidou-se provisoriamente como um "caldeirão de experiências sociais autônomas". Todavia, o mais impressionante e, em alguma medida, gerador de certo desconforto acaba sendo a convicção da linha argumentativa. Fundamentada ao rés do chão das lutas travadas em torno da "tarifa zero" (contraditoriamente uma "utopia" viável do ponto de vista econômico, para usarmos a língua dos capitalistas), ela aponta na direção de um curso histórico ascendente; a certeza de que "Não começou em Salvador, não vai terminar em São Paulo" decorre do inventário de revoltas populares instantâneas, crescentes nos últimos anos, embora invisíveis aos olhos embotados pelo afastamento crítico e concreto de parte considerável da intelectualidade (incluindo a de esquerda) do país. Uma categoria, em larga medida, distanciada das práticas de militância e insensível às situações de rotina desgraçada e inenarrável que encontra nas condições humilhantes do transporte popular urbano uma de suas imagens mais viscerais (vale dizer, humilhação e violência urbanas não somente pouco estudadas como também pouco dimensionadas, se pensarmos que se trata de um cotidiano de vivências de sofrimento que geralmente precedem e sucedem o próprio trabalho, este sim, em muitos casos não uma, mas sobretudo $a$ vivência massacrante dos indivíduos - aliás, não seria justamente a dificuldade em conseguir atuar dentro dos outros ambientes de exposição e humilhação o calcanhar de Aquiles do MPL, o qual encontra força apenas enquanto a pauta da "tarifa zero" não é viabilizada pela reorganização dispendiosa das planilhas de custos e das negociações orçamentárias do poder público?).

A bem da verdade, depois de junho de 2013, o tema da mobilidade urbana passou a frequentar variados matizes do articulismo de opinião. 
Faz toda diferença, entretanto, quando os problemas infernais da cidade não são resumidos a ineficiências técnico-administrativas. Encarados nos termos da luta de classes, a exemplo do MPL, Ermínia Maricato, Carlos Vainer e David Harvey desenvolvem reflexões argutas sobre as articulações que entrelaçam o desenvolvimento das metrópoles aos imperativos da acumulação capitalista. A regra metropolitana quase sempre revela a vigência absoluta de estruturas verticalizadas e impiedosas que, segundo a ex-ministra do governo Lula, fazem da metrópole um campo de batalha "entre aqueles que querem dela melhores condições de vida e aqueles que visam apenas extrair ganhos". Que a cidade, após a consolidação do capitalismo industrial, torna-se o principal palco dos conflitos sociais, não resta dúvida. Mas a transformação extremada do urbano em ativo financeiro, especialmente no Brasil, resulta do coroamento de um projeto desenhado e orquestrado pelo poder público em aliança com a burguesia (local e estrangeira) da construção civil, da especulação imobiliária, da indústria automotiva e do capital financeiro, sobretudo a partir de 2008, quando a crise mundial passa a exigir medidas de emergência por parte do governo brasileiro que, por sua vez, responde com a intensificação do Programa de Aceleração do Crescimento (PAC), que havia sido lançado no ano anterior. No entanto, como recorda Carlos Vainer, o terreno da expropriação já havia sido juridicamente preparado em 2001, quando brechas foram criadas no interior do próprio Estatuto da Cidade, produzindo uma nova tecnologia política - a "democracia direta do capital" - pela qual os grandes investidores decidem sozinhos os destinos da cidade que, do ponto de vista civil, jurídico, político e econômico, vive uma espécie de regime de exceção. Não por acaso, a última década consolida o Brasil no plano internacional como espaço privilegiado para megaeventos e meganegócios, mas o que muitos não imaginavam é que a gentrificação urbana, a ampliação das zonas periféricas e a crise da mobilidade desencadeariam megaprotestos.

É possível identificar pontos de inflexão que unem e ao mesmo tempo permitem a transposição das especificidades locais ao contexto estrangeiro. O caráter interdependente entre o modelo irracional de urbanização e o próprio modo de produção capitalista ganha concretude e visibilidade nas novas conformações metropolitanas, enquanto processo global. Deste ângulo, o ensaio de Harvey apresenta as maiores (e melhores) mediações. Em franco gesto de heterodoxia intelectual, a definição tomada de empréstimo de Robert Park (um dos fundadores da Escola de Chicago), que via a cidade como um "mundo onde se vive de acordo com o desejo de seu coração", é contraposta à tensão civil semeada pela fratura social e urbana, de um lado confinando as 
elites financeiras e as camadas mais favorecidas em "fragmentos fortificados" e, de outro, empilhando os trabalhadores rebaixados em favelas monumentais. Indiscutivelmente, uma desintegração da vida coletiva que impede a cidade de ser expressão máxima e realização efetiva dos anseios humanos.

Em rota distinta, Mike Davis se dedica ao mesmo dilema. Na forma de crônica (repleta de perspicácia, ao combinar etnografia urbana e visada sociológica com pitadas de ironia e humor), descrevendo um caso bastante peculiar, ele nos fornece pistas a respeito de um fenômeno que poderia ser definido como a generalização do autoritarismo nos grandes centros urbanos. Não se trata, no entanto, da brutalidade promovida estritamente pelo braço institucional, mas antes das variações incivis que adquirem força em meio à degradação do cotidiano e se manifestam, por exemplo, no comportamento bélico dos motoristas enquanto trafegam pelas estradas e avenidas da Califórnia dentro de suas máquinas mortíferas, cada vez maiores e mais potentes. Para ele, "a hegemonia dos utilitários no trânsito dita a postura do rearmamento defensivo e a lógica do desencorajamento mútuo". Assim, a atual incipiência teórica e prática do Estado Democrático de Direito ganha nitidez através do contraste flagrante entre os ideais civilizatórios do liberalismo e o caráter excepcional das leis e dos direitos, espécie de estado de sítio permanente infiltrado não apenas no cotidiano da vida urbana, mas, também, nos recônditos mais ínfimos da subjetividade. A farsa do modelo societário burguês está tanto na estupidez do comportamento paranoico, violentador e profundamente narcisista dos chamados “cidadãos comuns" encasulados no interior de seus utilitários, quanto na conivência do poder público em relação aos imperativos de acumulação ilimitada da indústria automobilística (e também das companhias de seguro), produtores de acidentes, adoecimento e morte em número elevadíssimo, exatamente como as guerras, contudo, dentro dos limites dos próprios territórios nacionais. Em suma, a proliferação de um massacre civil, explicitamente antirrepublicano, perpetrado por todos contra todos nas situações mais rotineiras e convencionais.

Mas as afinidades entre o civil e o bárbaro não param por aí. O ensaio de Slavoj Žižek explora o prenúncio do divórcio entre capitalismo e democracia, agora em escala global. Traçando paralelos a partir da coincidência imprevista da insurreição popular que explodiu concomitantemente aqui e na Turquia, além de enfatizar o caráter ilusório da integração social promovida pela intensificação paradisíaca do capitalismo nos dois países, o filósofo também rebate a tese de que os problemas domésticos das nações, que nos últimos anos convivem com turbulências nas ruas, estejam inteiramente desatrelados da globalização 
capitalista crescente nas últimas décadas. Trata-se, para ele, de um processo mundializado, no qual

a tendência geral do capitalismo global é direcionada à expansão do reino do mercado, combinada ao enclausuramento do espaço público, à diminuição dos serviços públicos (saúde, educação, cultura) e ao aumento do funcionamento autoritário do poder político. (p.104)

O pano de fundo da análise, portanto, é a perspectiva de que não temos pela frente necessariamente um colapso sistêmico e estrutural do capitalismo, mas, sim, a aniquilação dos direitos sociais e o agravamento das condições materiais das populações, gerando desilusão política e focos de insurgência.

À luz da falência do welfarestate, como fica aquele Brasil anterior aos protestos, supostamente carregado de virtudes sociais, o qual "diziam que havia dado certo" (na boa lembrança de Roberto Schwarz)? Por vias imprevistas e quase inteiramente ocultas, pode-se dizer que Cidades rebeldes também contribui para reorientar o antigo debate acerca da formação nacional. Afinal, em algum sentido, estaria o país acertando os ponteiros com o chamado mundo desenvolvido? Uma das maneiras de se pensar a questão encontra ressonância na própria perspectiva da trinca de intelectuais estrangeiros que sugerem - cada um a seu modo a condição regressiva do relógio da história. Por um lado, a sensação de progresso na periferia seria, no fundo, o efeito da decadência do centro, condenado a encontrar no rebaixamento de seu próprio patamar civilizatório a face mais crua do capitalismo contemporâneo; por outro, o ingresso brasileiro (ainda que levemente tardio) no circuito global da indignação generalizada indica ao menos uma aclimatação, com sinal trocado. Outras tentativas de resposta, porém, passam pela interpretação do processo histórico local em termos específicos, sobretudo nas últimas duas décadas, no qual a hegemonia lulista serve de parâmetro maior. A vantagem crítica é que, depois de junho de 2013, qualquer balanço sobre o novo capitalismo brasileiro dispõe de uma demonstração de insatisfação popular impossível de ser escamoteada - e, desde que se abandone a antiga lógica "centro-periferia" que pautou o debate esquerdista brasileiro nos últimos cinquenta anos, quem sabe uma nova interpretação da dinâmica nacional (e também internacional), especialmente no que se refere à amplitude achatada da imaginação política, não poderia desvelar seus primeiros contornos? Como já foi dito, de uma forma ou de outra, todos os autores de Cidades rebeldes parecem levar em conta 
as contradições do "velho" e do "novo", em diferentes dimensões, muito embora, no caso de alguns a filiação afetiva - mal resolvida? - ao Partido da Ordem talvez tenha atolado o pensamento crítico no limbo das expectativas imobilizadas dentro das raias do "possível” ou, em outros termos, redimensionado a reflexão sobre a conjuntura política em torno da velha crença de que a pressão popular organizada poderia corrigir a atual rota do governo, até então pragmaticamente comprometido com a "governabilidade" enquanto fazia "ouvidos moucos" às demandas dos movimentos sociais - em geral adestrados ou praticamente impotentes.

O sociólogo Ruy Braga, um dos poucos a ressaltar os indícios de inquietação de parte da classe trabalhadora antes mesmo da sublevação, sustenta a hipótese de que a desconcentração de renda promovida pelo lulismo vem se mostrando cada vez mais frágil diante do desastre social que a reestruturação pós-fordista produziu no mundo do trabalho. Por isso, o "precariado" que foi às ruas - fração jovem e precarizada do proletariado nacional - estaria, sim, colocando em cheque a suposta integração que, há mais de uma década, garante o PT no poder (Partido que se pensa internamente como o verdadeiro protagonista da tão esperada formação nacional que, antes mesmo da República Velha, romanticamente já se projetava como nossa grande missão - ou miserável destino, dependendo do ponto de vista). Em todo caso, a reunião de diferentes interpretações do processo histórico brasileiro recente, com certeza, figura entre as contribuições do livro.

Sem mudar completamente de assunto, desperta-se ainda outros interesses quando se tem Cidades rebeldes em mãos. Ganham destaque, entretanto, os trabalhos de crítica da ideologia que examinam não apenas o travejamento imaginário variado dos manifestantes, por vezes reacionário, como também o papel desempenhado pelas redes sociais e pela mídia corporativa, além dos próprios limites da rebelião. No que se refere ao modus operandi das grandes empresas de comunicação, Silvia Viana transpõe as barreiras do consenso ao notar que a tentativa exasperada de transformação do pacifismo em dever funcionava como cristalização de exigências da classe proprietária: dividindo espaço com as cenas de violência, as "manifestações pacíficas eram exibidas e celebradas porque deixavam São Paulo trabalhar". Portanto, não é de se estranhar que, desde junho de 2013, a defesa aberta da repressão paradoxalmente seja disparada do tópos pacifista, sem complacência, encontrando no "protesto sem protesto" uma fórmula terapêutica conservadora da ordem, que precisa seguir imune a qualquer tipo de risco. Por outro lado, é inegável que a consciência reificada dos "indivíduos serializados", aos quais Mauro Luis Iasi se refere em linguagem sartreana, parece ter dado mostras de 
que, de fato, não é totalmente administrável. Reforçando a capacidade de controle e cooptação concentrada nas mãos dos donos do poder, Lincoln Secco por sua vez aponta para urgência de superação da "forma partidária sem vida interior".

Aqui, nos encontramos diante de um enquadramento sombrio, complexo na medida em que combina crise do modelo de integração, insurgência sui generis e novas tecnologias e dispositivos públicos e privados de contrainsurgência e dominação. Fica então a pergunta: Que fazer para que o momento se transforme em brecha política, isto é, como proceder coletivamente para que se instaure a hora e a "vez do direito social e da descriminalização dos movimentos sociais"?

Pensada conscientemente em termos prospectivos (o que agrava ainda mais a situação), a tarefa política delineada por Jorge Luiz Souto Maior é emblemática de uma regressão histórica peculiar que se revolve, forma ressacas cada vez mais violentas, mas, no entanto, teima em continuar desabando sobre si mesma. Como se sabe, a pauta dos direitos e da descriminalização do ativismo político existe no Brasil há pelo menos 35 anos, desde a derrota da luta armada durante o Regime Militar, no fim da década de 1970. Então, surge uma nova pergunta: O que significa, a partir do estrondo junino, a repetição das demandas republicanas (algo como um pedido de licença para simplesmente existir) quando uma ex-guerrilheira, atualmente reconhecida por suas virtudes empresariais, ocupa a cadeira da Presidência da República graças ao voto dos mais de 55 milhões de eleitores que, nas urnas eletrônicas, optaram pela continuidade do Partido dos Trabalhadores no poder? Por esse prisma, a ponderação mais determinante para se pensar o ponto de fuga da revolta talvez tenha partido de Felipe Brito e Pedro Rocha de Oliveira. A dupla carioca coloca a luta política em termos radicalmente inspiradores, muito embora reveladores do buraco negro que talvez tenha se consolidado como fundação de uma estrutura social cada vez mais pressionada pelos imperativos de capitalização perpétua - que precisam ser mantidos custe o que custar. Inventariando o esfarelamento das velhas formas de organização sindical e trabalhista no decorrer das duas últimas décadas, junto ao novo arsenal tecnológico e beligerante de gestão social dos conflitos disponível às classes dominantes, os dois pesquisadores apontam para a direção de uma igualmente nova guerra particular e cotidiana já em curso, sobretudo nas favelas e periferias, travada ainda com extrema debilidade por parte dos movimentos sociais oriundos desses territórios de pobreza, uma vez que, no limite, se mostram totalmente incapazes de romper com "o distanciamento perante os meios de produção". Buraco sem fundo, portanto, pelo qual será tragado todo e qualquer projeto de 
mudança dentro da ordem (sic), tal como a reforma política destacada por Venício A. de Lima, que também identifica a "crise de representação" como fenômeno social e político, muito embora parcialmente desarticulado da racionalidade econômica menos evidente?

Enfim, são apenas impressões sobre o conjunto de perspectivas em torno dos acontecimentos de junho de 2013. Terminada a leitura, por certo, permanecem muito mais dúvidas do que propriamente respostas. Entre elas, a sensação de que o Brasil atravessado pelo lulismo continua não sendo aquilo que se esperava, e, mais do que isso, parece de fato ter se tornado outro. Todavia, se a "tremenda fábrica de consentimento" (na expressão precisa de Paulo Arantes) começa a apresentar dificuldades, significa que a máscara caiu para parte considerável da população, e os velhos paladinos do progresso, mais do que nunca, agora podem ser reconhecidos como verdadeiros coveiros da esperança. Entretanto, ao menos por ora, especialmente em vista dos desdobramentos lancinantes produzidos direta ou indiretamente pela grande revolta (desde greves organizadas à revelia das direções sindicais pelegas, passando por surtos de rituais de linchamento espalhados pelo país e culminando com um incremento técnico, material e informacional até então inaudito das forças públicas de repressão, incluindo alterações no ordenamento jurídico) o entusiasmo deve permanecer de braços dados com a reticência - aliás, Cidades rebeldes cumpre em parte este papel. Como nos alerta Ermínia Maricato, há um sentido que orienta o pensamento crítico, o qual, uma vez derrotado, provavelmente assistiria à execução da inteligência - afinal, é sempre "da vida, do tempo perdido, mas também da morte que estamos tratando". 
